\title{
3 Pengaruh Kompetensi Pegawai terhadap Kualitas Pelayanan (Studi kasus Kelurahan Bukit Betung)
}

\author{
Yuni Astria Safitri \\ yuniastriasafitri3@gmail.com \\ STISIPOL Pahlawan 12
}

\begin{abstract}
ABSTRAK
Penelitian ini bertujuan untuk melihat pengaruh dari kompetensi pegawai terhadap kualitas pelayanan di Kelurahan Bukit Betung. Jenis penelitian ini adalah korelasional dengan pendekatan kuantitatif. Subjek dan lokasi penelitian adalah warga dan pegawai di Kelurahan Bukit Betung. Uji reliabilitas dan uji validitas dalam penelitian ini digunakan untuk melihat valid atau tidaknya kuesioner penelitian, sedangkan uji t dilakukan untuk mengetahui apakah variabel bebas mempunyai pengaruh yang signifikan terhadap variabel terikat. Teknik analisis data menggunakan analisis statistik deskriptif dan statistik inferensial dengan menggunakan analisis regresi linier sederhana. Hasil penelitian menunjukkan bahwa kompetensi pegawai terhadap kualitas pelayanan di Kelurahan Bukit Betung kurang berpengaruh secara signifikan, dengan variabel sebesar 13,6\%. Kompetensi merupakan gabungan dari berbagai dimensi yakni sikap, pengetahuan dan kemampuan. Adapun kualitas pelayanan merupakan gabungan dari berbagai dimensi, yakni keandalan, daya tangkap, jaminan, perhatian, dan bukti langsung.
\end{abstract}

Kata kunci: kompetensi pegawai, kualitas pelayanan, pelayanan publik

\begin{abstract}
This research look at the effect of the employee competence service quality in the village office of Bukit Betung. The type of this research is correlational with a quantitative approach. The subject and location of the research were residents and employees in the village office of Bukit Betung. The reliability test and validity test in this research were used to look valid or not the questionnaire research, while the test was conducted to know whether the independent variable had a significant effect on the dependent variable. The techniques data analysis using descriptive statistical analysis and inferential statistics by used simple linear regression analysis. The results showed that the effect of employee competency on service quality in the village office of Bukit Betung significantly less effect with the variable of 13.6\%. Competence is a combination of various dimensions that is attitudes, knowledge, and abilities. While the quality of service is a combination of various dimensions that is reliability, comprehension, guarantee, attention, and direct evidence.
\end{abstract}

Keywords: employee competency, service quality, public service 


\section{PENDAHULUAN}

Negara merupakan organisasi yang sah dan memiliki kedaulatan yang dibentuk berdasarkan undang-undang untuk menyelenggarakan suatu pemerintahan serta memberikan pelayanan kepada rakyat berdasarkan pada kepentingan publik atau masyarakat umum. Negara merupakan organisasi yang berkuasa dengan dipegang dan digerakkan oleh manusia, memiliki sebuah tempat untuk mencapai tujuan bersama.

Selain mempunyai tujuan, negara juga memiliki fungsi. Fungsi negara adalah sebagai pelayanan, pemberdayaan, dan pembangunan. Pelayanan merupakan hak masyarakat Indonesia dan berasaskan pada keterbukaan informasi, akuntabilitas, dan persamaan hak bagi warga agar kebutuhan pada pelayanan publik dapat terpenuhi dan terselenggara dengan baik.

Pelayanan menjadi kunci keberhasilan dalam berbagai usaha ataupun kegiatan yang bersifat jasa. Bahkan pelayanan menjadi pembahasan yang menarik di kalangan masyarakat, organisasi, hingga tingkat manajemen perusahaan. Pelayanan yang memiliki kualitas yang baik menjadi salah satu wujud tata kelola pemerintahan yang baik (good governance). Konsep kualitas pelayanan dapat dipahami melalui perilaku masyarakat dalam mencari, membeli, menggunakan, dan mengevaluasi suatu produk atau pelayanan yang diharapkan dapat memuaskan kebutuhan mereka. Salah satu faktor yang perlu dipertimbangkan dalam mencapai kualitas pelayanan publik yang baik di antaranya adalah kompetensi yang dimiliki oleh pegawai.
Salah satu penyelenggara dalam pelayanan publik adalah kelurahan, yang merupakan bagian dari wilayah administrasi yang dikepalai seorang lurah. Pembentukan organisasi kelurahan dalam penelitian ini merujuk pada Peraturan Daerah Nomor 1 Tahun 2005 tentang Pembentukan Organisasi Kecamatan dan Kelurahan dalam Kabupaten Bangka, dan Peraturan Bupati Nomor 17 Tahun 2010 tentang Penjabaran Tugas dan Fungsi Kecamatan dan Kelurahan dalam Kabupaten Bangka.

\section{LANDASAN TEORI}

Kualitas Pelayanan

Menurut Sinambela dan kawan-kawan (dalam Mulyadi, 2016: 39), pelayanan publik adalah setiap kegiatan yang dilakukan oleh pemerintah terhadap sejumlah manusia yang memiliki setiap kegiatan yang menguntungkan dalam suatu kumpulan atau kesatuan, dan menawarkan kepuasan meskipun hasilnya tidak terikat pada suatu produk secara fisik.

Menurut Undang-Undang Nomor 25 Tahun 2009, pelayanan publik adalah kegiatan atau rangkaian kegiatan dalam rangka pemenuhan kebutuhan pelayanan sesuai dengan peraturan perundang-undangan bagi setiap warga negara dan penduduk atas barang, jasa dan/atau pelayanan administratif yang disediakan oleh oleh penyelenggara pelayanan publik.

Menurut Zeithami dan kawan-kawan (dalam Semil, 2016: 47), kualitas pelayanan adalah tingkat kesenjangan antara harapan-harapan 
atau keinginan-keinginan konsumen dengan kenyataan yang mereka alami.

Dari pengertian dan pendapat ahli di atas, peneliti menyimpulkan bahwa pelayanan publik adalah segala kegiatan yang berhubungan dengan pelayanan yang dilakukan oleh penyelenggara pelayanan publik dalam rangka memenuhi kebutuhan publik berupa barang atau jasa atau hal-hal yang bersifat administratif. Dalam pelaksanaannya, pelayanan publik memiliki beberapa indikator. Indikator inilah yang akan digunakan untuk meningkatkan kualitas pelayanan yang diberikan kepada publik.

Menurut Fitzsimmons, Zeithami, dan Bitner yang dikutip oleh Tjiptono (dalam Mulyadi, 2016: 192), ada lima indikator dalam pelayanan publik, yaitu realibility (keandalan) yang ditandai dengan pemberian pelayanan yang tepat dan benar; tangibles (bukti langsung) yang ditandai degan penyediaan sumber daya manusia dan sumber daya lainnya; responsiveness (daya tanggap) yang ditandai dengan keinginan melayani konsumen dengan cepat; assurance (jaminan) yang ditandai dengan tingkat perhatian, dan empathy (empati) yang ditandai dengan tingkat kemampuan untuk mengetahui keinginan dan kebutuhan konsumen.

\section{Kompetensi Pegawai}

Peranan sumber daya manusia (SDM) menjadi sangat penting di dalam menciptakan pelayanan yang efektif dan efisien. Kompetensi menjadi salah satu salah satu dalam pengembangan SDM untuk menciptakan kualitas pelayanan kepada masyarakat. Kompetensi menurut Spencer dan Spencer (dalam Batinggi dan Ahmad, $2014: 5.22$ ) adalah karakteristik yang mendasari seseorang yang berkaitan dengan efektivitas kinerja individu dalam pekerjaannya. Kompetensi terdiri dari kompetensi teknis dan kompetensi non-teknis. Kompetensi teknis terdiri dari pengetahuan dan kemampuan, sedangkan kompetensi non-teknis terdiri dari sikap seperti keluwesan, semangat, dan fleksibilitas.

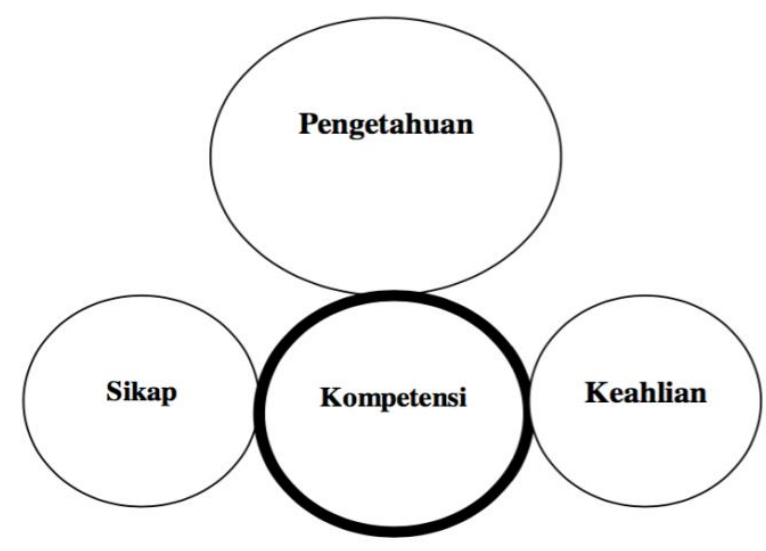

Gambar 1. Indikator-indikator yang Mempengaruhi Pembentukan Kompetensi.

\section{ETODOLOGI}

Desain penelitian ini menggunakan pendekatan kuantitatif. Menurut Husein (2007: 37), penelitian kuantitatif adalah penelitian yang didasarkan pada data yang dapat dihitung yang digunakan untuk menghasilkan penafsiran kuantitatif yang kokoh. Penelitian kuantitatif digunakan untuk menguji teori-teori tertentu dengan cara meneliti hubungan antar-variabel. 
Penelitian ini juga menggunakan dua jenis variabel. Variabel yang digunakan adalah variabel bebas (independent variable), yakni kompetensi, dan variabel terikat (dependent variable), yakni kualitas pelayanan.

Lokasi yang diambil berada di Kelurahan Bukit Betung, yang beralamatkan di Jalan Bukit Betung, Kecamatan Sungailiat, Kabupaten Bangka, Provinsi Kepulauan Bangka Belitung. Kelurahan Bukit Betung merupakan salah satu kelurahan pemekaran. Pemekaran wilayah kelurahan ini diatur dalam Peraturan Daerah Kabupaten Bangka Nomor 11 Tahun 2012.

Sumber data yang digunakan dalam penelitian ini diperoleh melalui dua sumber yakni, sumber data primer dan sumber data sekunder. Data primer adalah data yang secara langsung peneliti dapat dari sumber pertama, sedangkan data sekunder adalah data yang diperoleh secara tidak langsung atau melalui sumber kedua dan seterusnya (Prasetyo, 2014: 4-12).

Pengumpulan data dalam penelitian ini menggunakan beberapa teknik. Teknik pengumpulan data digunakan agar data-data yang terkumpul dapat dipertanggungjawabkan kebenarannya. Pengumpulan data yang digunakan dalam penelitian ini adalah kuesioner dan riset perpustakaan.

Analisis data dalam penelitian ini menggunakan analisis statistik deskriptif. Uji instrumen terdiri dari uji validitas dan uji

reliabilitas. Uji asumsi klasik terdiri dari uji normalitas dan uji linieritas. Analisis regresi linier sederhana terdiri dari koefisien korelasi dan koefisien determinasi, dan uji hipotesis menggunakan uji t.

\section{HASIL DAN PEM BAHASAN}

Kelurahan Bukit Betung merupakan salah satu penyelenggara layanan publik yang menjadi bagian wilayah administrasi yang dikepalai seorang lurah. Kelurahan merupakan unit pemerintahan yang setingkat dengan desa. Undang-Undang yang mengatur tentang kelurahan diatur dalam Peraturan Pemerintah Republik Indonesia Nomor 73 Tahun 2005.

\section{Profil Responden}

Berdasarkan data penelitian yang dilakukan dengan penyebaran kuesioner, diperoleh data responden variabel $\mathrm{X}$ dan variabel $\mathrm{Y}$ berikut ini. 
a) Jenis kelamin

\begin{tabular}{|c|c|c|c|}
\hline No. & $\begin{array}{c}\text { Jenis } \\
\text { Kelamin }\end{array}$ & $\begin{array}{c}\text { Jumlah } \\
\text { (orang) }\end{array}$ & $\begin{array}{c}\text { Frekuensi } \\
(\boldsymbol{\%})\end{array}$ \\
\hline 1. & Laki-laki & 7 & 54 \\
\hline 2. & Perempuan & 6 & 46 \\
\hline \multicolumn{2}{r|}{ TOTAL } & $\mathbf{1 3}$ & $\mathbf{1 0 0}$ \\
\hline
\end{tabular}

Dari tabel di atas persentase responden laki-laki sebesar 54\% (7 orang), dan persentase responden perempuan sebesar $46 \%$ (6 orang).

b) Tingkat pendidikan

\begin{tabular}{|c|c|c|c|}
\hline No. & $\begin{array}{c}\text { Tingkat } \\
\text { Pendidikan }\end{array}$ & $\begin{array}{c}\text { Jumlah } \\
\text { (orang) }\end{array}$ & $\begin{array}{c}\text { Frekuensi } \\
(\boldsymbol{\%})\end{array}$ \\
\hline 1. & SMK & 2 & 15 \\
\hline 2. & SMA & 5 & 39 \\
\hline 3. & D-2 & 0 & 0 \\
\hline 4. & D-3 & 0 & 0 \\
\hline 5. & S-1 & 6 & 46 \\
\hline 6. & S-2 & 0 & 0 \\
\hline \multicolumn{2}{r|}{ TOTAL } & $\mathbf{1 3}$ & $\mathbf{1 0 0}$ \\
\hline
\end{tabular}

Dari tabel di atas dapat diketahui bahwa mayoritas tingkat pendidikan terakhir responden adalah SMA/SMK. Dari tabel di atas persentase responden tingkat pendidikan terakhir ini terdiri dari SMK, SMA, D-2, D-3, S-1 dan S-2. Untuk tingkat pendidikan SMK sebanyak 2 orang, SMA, 5 orang; D-2, 0 orang; D3, 0 orang; S-1, 6 orang; S-2, 0 orang.

c) Masa kerja

\begin{tabular}{|l|l|c|c|}
\hline No. & \multicolumn{1}{|c|}{ Masa Kerja } & Jumlah (orang) & Frekuensi (\%) \\
\hline 1. & $<5$ tahun & 4 & 31 \\
\hline 2. & $5-10$ tahun & 3 & 23 \\
\hline 3. & $11-15$ tahun & 5 & 38 \\
\hline 4. & $16-20$ tahun & 0 & 0 \\
\hline 5. & $21-25$ tahun & 0 & 0 \\
\hline 6. & $>25$ tahun & 1 & 8 \\
\hline
\end{tabular}




\section{Total}

13

100

Dari tabel di atas dapat diketahui bahwa mayoritas tingkat pendidikan terakhir responden adalah SMA/SMK. Dari tabel tersebut, persentase responden tingkat pendidikan terakhir ini terdiri dari SMK, SMA, D2, D3, S1 dan S2. Untuk tingkat pendidikan SMK; 2 orang, SMA; 5 orang, D2; 0 orang, D3;0 orang, S1;6 orang dan S2; 0 orang.

Variabel Y

a) Jenis kelamin

\begin{tabular}{|c|c|c|c|}
\hline No. & Jenis Kelamin & $\begin{array}{c}\text { Jumlah } \\
\text { (orang) }\end{array}$ & $\begin{array}{c}\text { Frekuensi } \\
(\%)\end{array}$ \\
\hline 1. & Laki-Laki & 59 & 62 \\
\hline 2. & Perempuan & 36 & 38 \\
\hline \multicolumn{2}{|c|}{ Total } & $\mathbf{9 5}$ & $\mathbf{1 0 0}$ \\
\hline
\end{tabular}

Dari tabel di atas dapat diketahui bahwa mayoritas responden berjenis kelamin laki-laki sebanyak 59 orang $(62 \%)$. Untuk responden yang berjenis kelamin perempuan sebanyak 36 orang (38\%).

b) Tingkat pendidikan

\begin{tabular}{|c|c|c|c|}
\hline No. & $\begin{array}{c}\text { Tingkat } \\
\text { Pendidikan }\end{array}$ & $\begin{array}{c}\text { Jumlah } \\
\text { (orang) }\end{array}$ & $\begin{array}{c}\text { Frekuensi } \\
(\boldsymbol{\%})\end{array}$ \\
\hline 1. & Paket C & 1 & 1 \\
\hline 2. & SD & 4 & 4 \\
\hline 3. & SMP & 5 & 6 \\
\hline 4. & SMA & 39 & 41 \\
\hline 4. & SMK & 10 & 11 \\
\hline 5. & STM & 3 & 3 \\
\hline 7. & D-3 & 5 & 5 \\
\hline 8. & S-1 & 23 & 24 \\
\hline 9. & S-2 & 5 & 5 \\
\hline \multicolumn{2}{|c|}{ Total } & $\mathbf{9 5}$ & $\mathbf{1 0 0}$ \\
\hline
\end{tabular}

Dari hasil penelitian, tabel di atas dapat diketahui bahwa tingkat pendidikan di Kelurahan Bukit Betung terdiri dari Paket C sebanyak 1 orang (1\%), SD sebanyak 4 orang (4\%), SMP sebanyak 5 orang (6\%), SMA sebanyak 39 orang (41\%), SMK sebanyak 10 orang (11\%), STM 
sebanyak 3 orang (3\%), D-3 sebanyak 5 orang (5\%), S-1 sebanyak 23 orang (24\%), dan S-2 sebanyak 5 orang $(5 \%)$.

\section{Analisis Statistik Deskriptif}

Statistik deskriptif dapat digunakan bila peneliti hanya ingin mendeskripsikan data sampel, dan tidak ingin membuat kesimpulan yang berlaku untuk populasi tempat sampel diambil. Di dalam statistik deskriptif hanya digambarkan objek yang diteliti tanpa melakukan analisis terlebih dahulu terhadap apa yang diteliti dan membuat suatu kesimpulan yang berlaku umum (Sugiyono, 2008: 17). Berikut tabel statistik deskriptif dari temuan peneliti.

\begin{tabular}{|l|r|l|l|}
\hline \multicolumn{1}{|c|}{ Descriptive Statistics } \\
\hline & $\mathrm{N}$ & Mean & Std. Deviation \\
\hline Kompetensi & 13 & 37.85 & 5.490 \\
$\begin{array}{l}\text { Kualitas } \\
\text { Pelayanan } \\
\text { Valid N } \\
\text { (listwise) }\end{array}$ & 95 & 69.16 & 11.980 \\
\hline
\end{tabular}

Dilihat dari tabel statistik deskriptif di atas, nilai rata-rata kualitas pelayanan sebesar 69,16, atau lebih tinggi dari nilai kompetensi, yaitu sebesar 37,85. Standar deviasi atau simpangan baku kualitas pelayanan sebesar 11,980, atau lebih besar dari nilai kompetensi yaitu sebesar 5,490. Semakin besar nilai standar deviasi, menandakan semakin menyebar data pengamatan yang dilakukan di Kelurahan Bukit Betung, dan setiap data memiliki kecenderungan berbeda-beda.

Adapun besar $\mathrm{N}$ untuk variabel kompetensi adalah 13, sedangkan besar $\mathrm{N}$ untuk variabel kualitas pelayanan adalah 95 atau menunjukkan banyaknya jumlah responden yang dianalisis.

\section{Uji Asumsi Klasik}

- Hasil uji normalitas

Uji normalitas berguna untuk menilai sebaran data kepada responden yang dituju untuk melakukan penelitian, data yang disebar tersebut apakah berdistribusi normal ataukah tidak. Uji normalitas yang digunakan dalam penelitian ini adalah Kolmogorov-Smirnov Test.

Menurut Santoso (2004: 212), uji normalitas data menggunakan Kolmogorov-Smirnov adalah membandingkan Asymptotic Significance dengan $\alpha=5 \%$. Dasar penarikan kesimpulan adalah data dikatakan berdistribusi normal jika nilai Asymptotic Significance $>0,05$. 
Dilihat dari tabel di bawah ini, berdasarkan hasil uji normalitas diketahui bahwa nilai signifikansi 0,100>0,05 sehingga dapat disimpulkan bahwa nilai residual berdistribusi normal.

\section{One-Sample Kolmogorov-Smirnov Test}

\begin{tabular}{|c|c|c|}
\hline & & $\begin{array}{r}\text { Standardized } \\
\text { Residual }\end{array}$ \\
\hline \multicolumn{2}{|l|}{ N } & 13 \\
\hline Normal & Mean & .0000000 \\
\hline \multirow[t]{2}{*}{ Parameters } & Std. & \\
\hline & & .95742711 \\
\hline \multicolumn{2}{|c|}{ Deviation } & \\
\hline \multicolumn{2}{|c|}{$\begin{array}{l}\text { Most Extreme } \\
\text { Absolute }\end{array}$} & .216 \\
\hline Differences & Positive & .216 \\
\hline \multicolumn{2}{|c|}{ Negative } & -.169 \\
\hline \multicolumn{2}{|c|}{ Test Statistic } & .216 \\
\hline \multicolumn{2}{|c|}{ Asymp. Sig. (2-tailed) } & $.100^{c}$ \\
\hline
\end{tabular}

a. Test distribution is Normal.

b. Calculated from data.

c. Lilliefors Significance Correction.

d.Hasil uji linieritas

Uji linieritas bertujuan untuk menguji hubungan antara variabel terikat dan variabel bebas yang bersifat linier atau garis lurus. Untuk mengetahui gambaran antara variabel bebas dan variabel terikat, lihat tabel di bawah ini:

\begin{tabular}{|c|c|c|c|c|c|c|c|}
\hline & & & $\begin{array}{l}\text { Sum } \\
\text { of } \\
\text { Squar } \\
\text { es }\end{array}$ & & $\begin{array}{l}\text { Mean } \\
\text { Squar } \\
\square\end{array}$ & & \\
\hline \multirow{6}{*}{$\begin{array}{l}\text { Kualit } \\
\text { as } \\
\text { Pelay } \\
\text { anan } \\
\text { * } \\
\text { Komp } \\
\text { etensi }\end{array}$} & & (Combir & & 6 & $\begin{array}{c}172.3 \\
47\end{array}$ & 1.516 & .313 \\
\hline & n & Linearity & $\begin{array}{r}083 \\
232 . \\
5\end{array}$ & 1 & $\begin{array}{c}232.5 \\
18\end{array}$ & $\begin{array}{c}2.04 \\
6\end{array}$ & .203 \\
\hline & ups & & 18 & 5 & $\begin{array}{c}160.3 \\
13\end{array}$ & 1.41 & \\
\hline & & Linearity & & & & & \\
\hline & & $\begin{array}{l}\text { Within } \\
\text { Group } \\
\text { s }\end{array}$ & $\begin{array}{r}681 . \\
9\end{array}$ & 6 & $\begin{array}{c}113.6 \\
53\end{array}$ & & \\
\hline & & Total & $\begin{array}{r}1716 \\
\text { กחก }\end{array}$ & $\begin{array}{l}1 \\
2\end{array}$ & & & \\
\hline
\end{tabular}


Berdasarkan hasil uji linieritas diketahui nilai signifikansi deviation from linierity adalah sebesar 0,340. Nilai signifikansi deviation from linierity $0,340>0,05$ maka dapat disimpulkan bahwa terdapat hubungan yang linier antara kompetensi pegawai dengan kualitas pelayanan di Kelurahan Bukit Betung.

•Hasil uji hipotesis

Menurut Ghozali (2013: 98), uji t pada dasarnya menunjukkan seberapa jauh pengaruh suatu variabel independen dalam menjelaskan variasi-variasi variabel dependen tersebut. Pengujian ini dilakukan untuk mengetahui apakah kompetensi mempunyai pengaruh yang signifikan terhadap kualitas pelayanan.

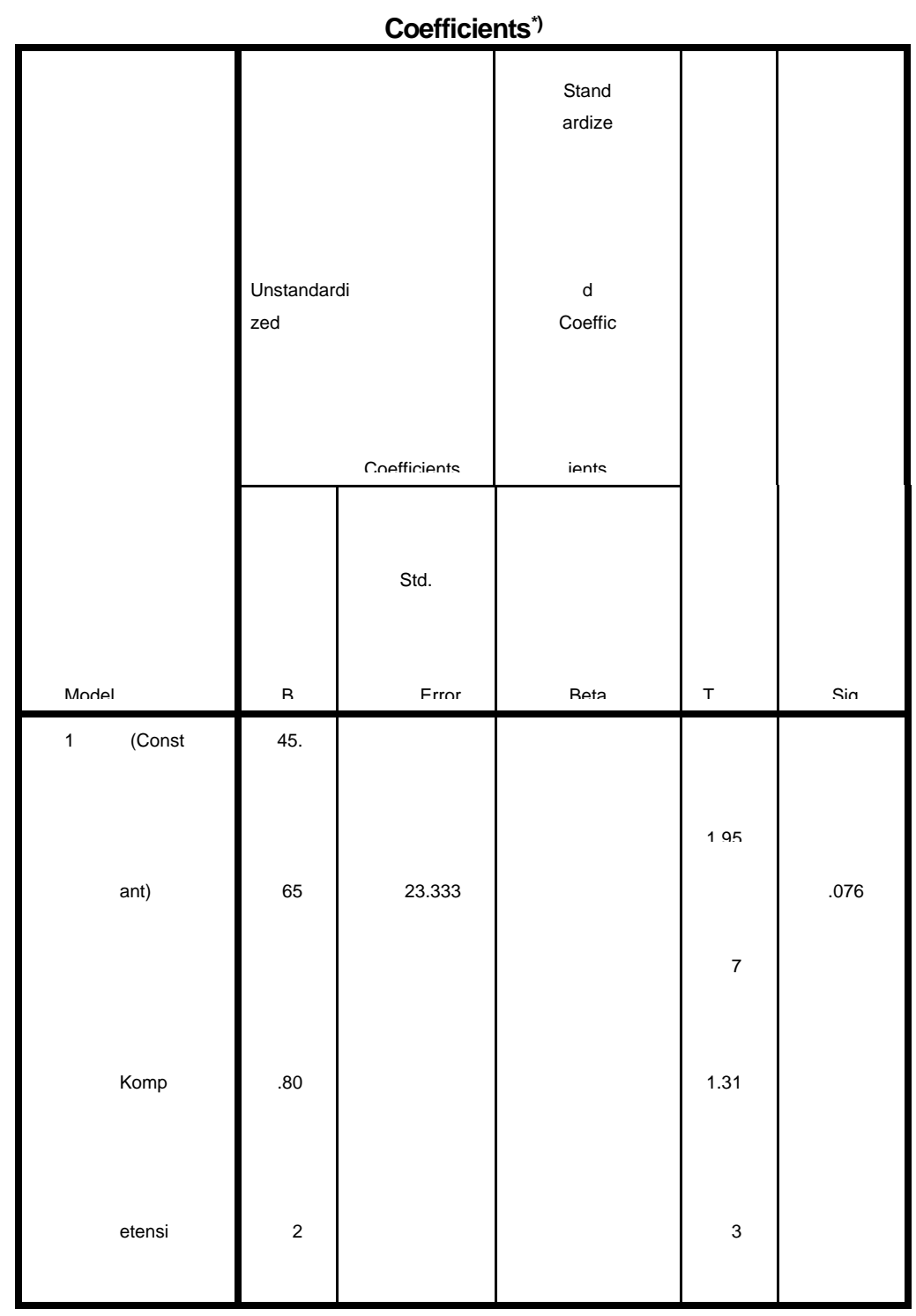

*) Dependent Variable: Kualitas Pelayanan 


\section{KESIMPULAN \& SARAN}

\section{Kesimpulan}

Berdasarkan hasil penelitian, dapat ditarik kesimpulan sebagai berikut:

1. Terdapat pengaruh positif antara Kompetensi Pegawai terhadap Kualitas Pelayanan di Kelurahan Bukit Betung. Akan tetapi, pengaruh tersebut kurang berpengaruh secara signifikan. Adapun signifikansinya 0,216 lebih besar 0,05 sehingga $\mathrm{H}_{0}$ diterima dan $\mathrm{H}_{1}$ ditolak.

2. Diketahui nilai thitung lebih kecil dari tabel $(1,313 \leq$ 1,795), sehingga tidak terdapat pengaruh yang signifikan antara Kompetensi Pegawai terhadap Kualitas Pelayanan di Kelurahan Bukit Betung.

3. Kontribusi pengaruh variabel kompetensi pegawai (X) terhadap kualitas pelayanan (Y) yang ditunjukkan oleh nilai $\mathrm{R}$ Square sebesar $0,136 \%$ atau $13,6 \%$ dan sisanya sebesar $86,4 \%$ dipengaruhi oleh faktor-faktor lain yang tidak dihitung dalam penelitian ini, seperti faktor usia, masa kerja, jenis kelamin, dan jenjang pendidikan.

\section{Saran}

Dengan adanya penelitian inidisarankan untuk dapat dilakukan penambahan tenaga honorer/aparatur sipil negara (ASN) di bagian teknologi informasi (TI). Hal ini dikarenakan belum tersedianya pemberitaan secara up to date atau terbarukan, baik di media sosial maupun situs resmi, terkait proses pengurusan administrasi kependudukan di Kelurahan Bukit Betung.

\section{DAFTAR PUSTAKA}

Batinggi, Achmad, dan Badu, Ahmad. (2014). Manajemen Pelayanan Umum. Jakarta: Universitas Terbuka

Edison, Emron, dkk. (2016). Manajemen Sumber Daya Manusia. Bandung: Alfabeta

Ghozali, Imam. (2013). Aplikasi Analisis Multivarite dengan Program IBM SPSS 21 Update PLS Regresi, cetakan ke-4. Semarang: Badan Penerbit Universitas Diponegoro

Mulyadi, Dedy. (2016). Administrasi Publik untuk Pelayanan Publik. Bandung: Alfabeta Prasetyo, Bambang. (2014). Metode Penelitian Sosial. Tangerang: Universitas Terbuka Santoso, Singgih. (2004). Mengatasi Berbagai Masalah Statistik dengan SPSS Versi 11.5. Jakarta: Elex Media Komputindo

Semil, Nurmah. (2016). Pelayanan Prima Instansi Pemerintah. Jakarta: PrenadaMedia

Sugiyono. (2003). Metode Penelitian Administrasi. Bandung: Alfabeta - (2008). Metode Penelitian $K u a n t i t a t i f$ dan $R \& D$. Bandung: Alfabeta

Umar, Husein. (2005). Metode Penelitian. Jakarta: Salemba Empat

\section{Peraturan Perundang-undangan}

Undang-Undang Nomor 25 Tahun 2009 tentang Pelayanan Publik

Undang-Undang Nomor 73 Tahun 2005 tentang Kelurahan

Peraturan Bupati Nomor 17 Tahun 2010 tentang Penjabaran Tugas dan Fungsi

Kecamatan dan Kelurahan dalam Kabupaten Bangka

Peraturan Daerah Kabupaten Bangka Nomor 11 Tahun 2012 tentang Pembentukan Kelurahan Sinar Jaya Jelutung, Kelurahan Matras, Kelurahan 
Jelitik, Kelurahan Surya Timur, Kelurahan Lubuk Kelik, dan Kelurahan Bukit

Betung dalam Wilayah Kecamatan

Sungailiat di Kabupaten Bangka

Peraturan Daerah Nomor 1 Tahun 2005 tentang

Pembentukan Organisasi Kelurahan 
